\title{
How to Choose the Correct Branding? Application of Fuzzy VIKOR on Consumers Purchasing the Luxury Brand
}

\author{
Tienchin Wang ${ }^{1,}$ and Yenying Huang, *
}

\author{
${ }^{1}$ Department of International Business, National Kaohsiung University of Sciences and Technology, No.415, Jiangong \\ Rd., Kaohsiung City 807618, Taiwan \\ ${ }^{2}$ Department of International Business, National Kaohsiung University of Sciences and Technology, No.415, \\ Jiangong Rd., Kaohsiung City 807618, Taiwan \\ *Corresponding author. Email:1101405117@nkust.edu.tw
}

\begin{abstract}
This paper applies the fuzzy VIKOR method to the luxury brand decision-making behavior. The method adds the largest group utility with the smallest regret of alternatives on the basis of fuzzy theory to solve the multi-criteria decision-making problem. The research process and results show that the opinions of decision-making experts can be the epitome of consumers' buying behavior, brand managers can also make more accurate marketing strategies, and they will be more constructive in the use of future marketing communication budgets.
\end{abstract}

Keywords: "Fuzzy VIKOR”, "MCDM", "luxury brands”.

\section{INTRODUCTION}

Luxury consumption is essentially a conspicuous behavior to distinguish oneself from others, and luxury brands can be used as a social symbol of distinguishing status [1], [2].

Kim et al. and Shukla et al. found that the demand for luxury goods in the Asian market has grown rapidly [3], [2]. Chinese consumers play an important role in global luxury goods consumption, accounting for $31 \%$ of global purchases, followed by the United States with $24 \%$ and Europe with 18\% [4]. The study pointed out that from 1995 to 2013, the luxury goods industry grew by $7 \%$ every year, with revenue of nearly US $\$ 8.75$ billion; after that, it continued to grow at $9 \%$ until 2020 [5].

According to Chevalier and Mazzalovo [6], Luxury goods have fashion elements and leather products, including clothing, accessories, handbags, shoes, belts and any other overall appearance elements such as glasses, writing instruments, lighters, etc.

Wiedmann [7] pointed out that a consumer's perception of the value of luxury goods and purchase motivation depends not only on social factors, such as showing status, success, uniqueness and deepening impression, but also on the practicality of luxury goods. And personal utility. Therefore, consumers have many complicated thinking processes for luxury purchase decisions, and the criteria for the decision-making process have many vague meanings.

Decision-making is considered to be the process of identifying and selecting the best decision from several alternative possibilities according to different criteria [8].

Therefore, this study will use the fuzzy VIKOR method to explore consumers' multi-criteria and complex decision-making when purchasing luxury goods and how to choose a brand. Most of the decisionmaking is composed of various conflicting evaluation criteria, which play a vital role in daily life. This process shows ambiguity and uncertainty. In 1965, Zadeh proposed fuzzy logic (fuzzy set theory) based on mathematics to solve the uncertainties and contradictions of decision factors [9]. By using the form of linguistic variables or fuzzy numbers, nonlinear problems are simplified to find solutions in complex decision-making environments [8], [10]. 


\section{LITERATURE REVIEW}

\subsection{Perceived Quality}

Aaker and Joachimsthaler [11] defined consumers' perceived quality of the brand as the perceived overall quality level of consumer for a particular brand of product, or consumer's subjective satisfaction level of the product, or service of a brand for a particular purpose. The perceived quality is a special type of association, partly because perceived quality affects brand associations in many cases. Insch and McBride [12] proposed that the perceived quality of design is the consumer's evaluation about if the engineer combines design ideas with the product well and the quality and performance of the product. The so-called product manufacturing perception quality is a consumer's judgment about whether the material or the component of the product is good or not. Zeithaml [13] argued that perceived quality is an abstract concept, so his definition of perceived quality is "the consumer's overall assessment of a product's superiority." Petrick [14] defined perceived quality as "the value that the consumer put on a product with particular degree of excellence."

\subsection{The image of Country of Origin}

Kotler and Armstrong [15] defined the image of the country of origin as "the summary of people's impressions and beliefs toward a particular country." Narayana [16] argued that the image of the country of origin is "the aggregate image of the product of any particular country, which is perceived by the consumer about the full range." The Consumer stereotypes products of a particular nation, based on their understanding about the marketing advantages and disadvantages of a country's product in the past, wherein the country's products produce a halo effect, forming customers' overall knowledge of the country's products [17]. In addition, they also proposed four more prominent aspects about the image of the country of origin, namely, innovation, design, prestige, and craftsmanship; and found that the four aspects are highly correlated with factor analysis found that these four aspects can be combined into a single factor. Most studies regarded the image of the country of origin as multiple facets. Martin and Eroglu [18] refer to the fact that industrial purchasers and consumers have an engraved image of the country or the product, which affects purchasing decisions. In the case of using the country's image to evaluate products, it's found that the image of the country is influenced by how consumers perceive the people and the product of that country, and their emotion toward them.

\subsection{Product Information}

Rao and Monroe [19] proposed that product information affect how consumers evaluate a product. To add, according to Biehal and Chakravarti 's [20] research, it was found that there's a correlation between the consumer selection process and memory, indicating that consumers were making choices after learning information, and that consumers would recall different related information in the past as they made decisions. Peter and Olson [21] proposed that product information includes four aspects: the product itself, the product type, the brand, and consumer behavior mode. Consumers use relevant product information to evaluate the commodity to be purchased while choosing the products. Product information also affects the process that consumers look for products and their decisionmaking, indirectly affect consumers' willingness to buy. Brucks [22] summarizes product information into three points: Subjective Knowledge, which primarily measures how much a consumer knows about the product and represents the confidence that customers have in product information; Objective knowledge, the product information stored in the consumers' memory and to what extent that consumers really understand about the product; Experience-Bases knowledge, customers' total purchase experiences.

\section{METHOD}

Wang and Chang were created the fuzzy VIKOR method in 2005 [23] which can solve the conflicted situations with several standards. According to the mathematical model, fuzzy VIKOR can help decisionmakers to deal with multi-criteria problems through systematic process to identify "compromise solution" and "best solution" [8].

The fuzzy VIKOR method calculated process as below:

Step1: Organize a decision makers group, make practical alternatives and confirm the criteria. Let $n$ to indicate the "decision-makers", $m$ to indicate the "alternatives" and $k$ to indicate "evaluation criteria".

Step 2: Confirm linguistic variables and triangular fuzzy numbers. The membership function are showed as Equation (1)

$f_{\tilde{A}}(x)=\left\{\begin{array}{lr}0, & x<\mathrm{a}_{2} \\ \left(x-\mathrm{a}_{1}\right) /\left(\mathrm{a}_{1}-\mathrm{a}_{2}\right), \mathrm{a}_{1} & \leq x \leq \mathrm{a}_{2} \\ \left(\mathrm{a}_{3}-x\right) /\left(\mathrm{a}_{3}-\mathrm{a}_{2}\right), \mathrm{a}_{2} & \leq x \leq \mathrm{a}_{3} \\ 0, & x>\mathrm{a}_{3}\end{array}\right.$

Equation (2) are expressed the TFN (triangular fuzzy numbers) about $\tilde{A}$ and $\tilde{B}$. 
$\tilde{A}(+) \tilde{B}=\left(a_{1}, a_{2}, a_{3}\right)(+)\left(b_{1}, b_{2}, b_{3}\right)=\left(a_{1}+b_{1}, a_{2}+b_{2}, a_{3}+b_{3}\right)$

$\tilde{A}(-) \tilde{B}=\left(a_{1}, a_{2}, a_{3}\right)(-)\left(b_{1}, b_{2}, b_{3}\right)=\left(a_{1}-b_{3}, a_{2}-b_{2}, a_{3}-b_{1}\right)$

$\tilde{A}(\times) \tilde{B}=\left(a_{1}, a_{2}, a_{3}\right)(\times)\left(b_{1}, b_{2}, b_{3}\right)=\left(a_{1} b_{1}, a_{2} b_{2}, a_{3} b_{3}\right)$

$\tilde{A}(\div) \tilde{B}=\left(a_{1}, a_{2}, a_{3}\right)(\div)\left(b_{1}, b_{2}, b_{3}\right)=\left(a_{1} / b_{3}, a_{2} / b_{2}, a_{3} / b_{1}\right)$

$k \tilde{A}=\left(k a_{1}, k a_{2}, k a_{3}\right)$ and $\left(\tilde{A}^{-1}\right)=\left(\left(1 / a_{3}\right),\left(1 / a_{2}\right),\left(1 / a_{1}\right)\right)$

Step 3: Aggregated the fuzzy weight of criteria and fuzzy rating of alternatives from the decision-makers

$\tilde{w}_{j}=\frac{1}{n}\left[\sum_{e=1}^{n} \tilde{w}_{j}^{e}\right], j=1,2, \ldots, k$

And then, regard to $j$ criterion for the important weight of each criterion and the rating of each alternative in the $i$ th alternative:

$\tilde{w}_{i j}=\frac{1}{n}\left[\sum_{e=1}^{n} \tilde{w}_{i j}^{e}\right], i=1,2, \ldots, m$

Step 4: Produce the fuzzy decision matrix and compute the fuzzy weighted average

$$
\begin{array}{llll}
C_{1} & C_{2} & \cdots & C_{k}
\end{array}
$$

$\tilde{D}=\begin{gathered}\mathrm{A}_{1} \\ \mathrm{~A}_{2} \\ \vdots \\ \mathrm{A}_{m}\end{gathered}\left[\begin{array}{cccc}\tilde{x}_{11} & \tilde{x}_{12} & \cdots & \tilde{x}_{1 n} \\ \tilde{x}_{21} & \tilde{x}_{22} & \cdots & \tilde{x}_{2 n} \\ \vdots & \vdots & \ddots & \vdots \\ \tilde{x}_{m 1} & \tilde{x}_{m 2} & \cdots & \tilde{x}_{m k}\end{array}\right]$

$i=1,2, \ldots, m ; \quad j=1,2, \ldots, k$

$\tilde{W}=\left[\tilde{w}_{1}, \tilde{w}_{2}, \cdots, \tilde{w}_{k}\right], \quad j=1,2, \ldots, k$

Step 5: Calculating the FBV (fuzzy best value) and FWV (fuzzy worst value):

$\tilde{f}_{j}^{*}=\max _{i} \tilde{x}_{i j}, \tilde{f}_{j}^{-}=\min _{i} \tilde{x}_{i j}$

Step 6: Determine the values about the $\tilde{S}_{i}$ and $\tilde{R}_{i}$ (the sum of the distance and the maximum distance for the FBV):

$\tilde{w}_{j}\left(\tilde{f}_{j}^{*}-\tilde{x}_{i j}\right) /\left(\tilde{f}_{j}^{*}-\tilde{f}_{j}^{-}\right), \tilde{S}_{i}, \tilde{R}_{i}$

$\tilde{S}_{i}=\sum_{j=1}^{k} \tilde{w}_{j}\left(\tilde{f}_{j}^{*}-\tilde{x}_{i j}\right) /\left(\tilde{f}_{j}^{*}-\tilde{f}_{j}^{-}\right)$

$\tilde{R}_{i}=\max _{j}\left[\tilde{w}_{j}\left(\tilde{f}_{j}^{*}-\tilde{x}_{i j}\right) /\left(\tilde{f}_{j}^{*}-\tilde{f}_{j}^{-}\right)\right]$

Step 7: Determine $\tilde{S}^{*}, \tilde{S}^{-}, \tilde{R}^{*}, \tilde{R}^{-}, \tilde{Q}_{i}$ (maximum \& minimum majority rule or maximum $\&$ minimum group utility):

$$
\begin{aligned}
& \tilde{S}^{*}=\min _{i} \tilde{S}_{i}, \quad \tilde{S}^{-}=\max _{i} \tilde{S}_{i} \\
& \tilde{R}^{*}=\min _{i} \tilde{R}_{i}, \quad \tilde{R}^{-}=\max _{i} \tilde{R}_{i} \\
& \tilde{Q}_{i}=v\left(\tilde{S}_{i}-\tilde{S}^{*}\right) /\left(\tilde{S}^{-}-\tilde{S}^{*}\right)+ \\
& (1-v)\left(\tilde{R}_{i}-\tilde{R}^{*}\right) /\left(\tilde{R}^{-}-\tilde{R}^{*}\right)
\end{aligned}
$$

$v$ represents the weight of the strategy of the maximum group utility. If $v>0.5$, the decision means maximum majority rule, if $v=0.5$, the decision means individual regret of the opponent.

Step 8: Defuzzify triangular fuzzy number (maximizing set and minimizing set):

Maximizing set is defined by $R=\left\{\left(x, f_{R}(x)\right) \mid x \in R\right\}$ and

$f_{R}(x)= \begin{cases}\left(x-x_{1}\right) /\left(x_{2}-x_{1}\right), & x_{1} \leq x \leq x_{2} \\ 0 & \text { otherwise }\end{cases}$

Minimizing set is defined by $L=\left\{\left(x, f_{L}(x)\right) \mid x \in R\right\}$ and

$f_{L}(x)=\left\{\begin{array}{lr}\left(x-x_{2}\right) /\left(x_{1}-x_{2}\right), & x_{1} \leq x \leq x_{2} \\ 0 & \text { otherwise }\end{array}\right.$

Right utility $U_{R}\left(\tilde{Q}_{i}\right)=\sup \left(f_{\bar{Q}_{i}}(x) \wedge f_{R}(x)\right)$

Left utility $U_{L}\left(\tilde{Q}_{i}\right)=\sup _{x}\left(f_{\tilde{Q}_{i}}(x) \wedge f_{L}(x)\right)$

Total utility $U_{T}\left(\tilde{Q}_{i}\right)=\left[U_{R}\left(\tilde{Q}_{i}\right)+1-U_{L}\left(\tilde{Q}_{i}\right)\right] / 2$

If $Q_{i}$ are smaller, the alternative are better.

Step 9: Confirm a compromise solution.

1. Acceptable advantage:

$Q\left(a^{\prime \prime}\right)-Q\left(a^{\prime}\right) \geq D Q$

$D Q=1 / m-1=0.25$ if $m \leq 4)$

2. And then, acceptable stability in decision making: under this condition, $Q\left(a^{\prime}\right)$ must be $S\left(a^{\prime}\right)$ or/ and $R\left(a^{\prime}\right)$.

1 and 2 are both accepted for the calculation results.

Step 10: Choose $Q\left(a^{\prime}\right)$ as the best solution with the minimum of $Q_{i}$ 
Table 1. The Introduction of the 3 luxury brands

\begin{tabular}{|c|c|c|c|}
\hline & A1 & A2 & A3 \\
\hline Year established & 1947 & 1856 & 1954 \\
\hline Country of origin & Frence & U.K. & Frence \\
\hline introduction & $\begin{array}{l}\text { European famous luxury } \\
\text { goods. The product category } \\
\text { contains ready-to-wear } \\
\text { fashion, leather goods, } \\
\text { accessories, or footwear }\end{array}$ & $\begin{array}{l}\text { European famous luxury } \\
\text { goods. The product category } \\
\text { contains trench coats, leather } \\
\text { goods, footwear, fashion } \\
\text { accessories. }\end{array}$ & $\begin{array}{l}\text { European famous luxury } \\
\text { goods. The product category } \\
\text { contains luxury trunks and } \\
\text { leather goods to ready-to- } \\
\text { wear, shoes. }\end{array}$ \\
\hline
\end{tabular}

Table 2. The characteristics of the 5 decision-making experts

\begin{tabular}{|c|c|c|c|c|c|}
\hline & Gender & Age & Education & Work Experience & Occupation \\
\hline D1 & Female & 37 & BA & 15 & Opinion leader \\
\hline D2 & Male & 38 & MA & 18 & Shopping expert \\
\hline D3 & Male & 45 & BA & 20 & Manufacturing boss \\
\hline D4 & Male & 38 & MA & 15 & Distributoring boss \\
\hline D5 & Female & 50 & PHD & 30 & Industry consultant \\
\hline
\end{tabular}

Table 4. Each criterion's (brand) importance weight

\begin{tabular}{|c|c|c|c|c|c|c|c|c|c|c|c|c|c|c|c|}
\hline & \multicolumn{4}{|c|}{ A1 } & \multicolumn{4}{c|}{ A2 } & \multicolumn{4}{c|}{} \\
\hline & D1 & D2 & D3 & D4 & D5 & D1 & D2 & D3 & D4 & D5 & D1 & D2 & D3 & D4 & D5 \\
\hline C1 & MG & VP & F & G & G & G & VG & G & MP & VG & VP & G & G & F & F \\
\hline C2 & G & VP & G & VG & MG & F & G & VG & G & F & G & G & VG & MG & F \\
\hline C3 & G & VG & MP & G & VP & P & VP & MG & G & G & VG & VP & G & MP & G \\
\hline
\end{tabular}

\section{A NUMERICAL EXAMPLE}

Suppose a customer wants to choose a brand of the luxury brands. Three candidates about the brands (A1, A2, A3) (as Table 1) are to be evaluated by five decision-makers (D1, D2, D3, D4, D5) (as Table 2) in three criteria: perceived Quality $(\mathrm{C} 1)$, the image of country of origin (C2), and product Information (C3).

Step 1: This study produces a viable alternative (m) according to the seven decision criteria in step 1 and 5 decision- makers (n).

Step 2: According the research of Chen and Wang [8], we define the linguistic variables and corresponding fuzzy numbers as below: Very Low (VL) $(0.0,0.0,0.1)$, Low(L) $(0.0,0.1,0.3)$, Medium Low (ML) $(0.1,0.3,0.5)$, Medium(M) (0.3,0.5,0.7), Medium High (MH) $(0.5,0.7,0.9), \operatorname{High}(\mathrm{H})(0.7,0.9,1.0)$, Very High $(\mathrm{VH})$ $(0.9,1.0,1.0)$. And then, five decision-makers also use the importance weight of each criterion as Table 3

Table 3. The importance weight of each criterion

\begin{tabular}{|c|c|c|c|c|c|}
\hline & D1 & D2 & D3 & D4 & D5 \\
\hline C1 & H & M & ML & MH & VH \\
\hline C2 & M & H & M & H & MH \\
\hline C3 & VH & ML & M & M & VH \\
\hline
\end{tabular}

Step 3: Five decision-makers evaluate the rating of three international brands based on three criteria. The corresponding fuzzy numbers about the linguistic variables are showed as: Very Poor (VP) $(0.0,0.0,0.1)$, Poor(P) (0.0,1.0,3.0), Medium Poor (MP) (1.0,3.0,5.0), Fair(F) (3.0,5.0,7.0), Medium Good (MG) (5.0,7.0,9.0), Good $(\mathrm{G})(7.0,9.0,10)$, Very Good (VG) $(9.0,10,10)$, and the fuzzy decision matrix are showed as Table 4.

Step 4: Calculating the triangular fuzzy number (a1, a2, a3) by Equation (2), the $\mathrm{C} 1\left(\tilde{w}_{j}\right)$ fuzzy value is equal to $(0.50,0.68,0.82), \mathrm{C} 2:(0.50,0.70,0.86)$, and C3 : (0.50, 0.66, 0.78)

Step 5: And then, converting and combining the brand fuzzy rating about the three brands by Equation (3). A1 ( $\left.\tilde{w}_{i j}\right)$ fuzzy value in respect of $\mathrm{C} 1$ is equal to $(2.8,5.0,6.0)$, showed the fuzzy value as Table 5 .

Table 5. The A fuzzy value in respect of $\mathrm{C} 1$ value

\begin{tabular}{|l|c|c|c|}
\hline & A1 & A2 & A3 \\
\hline C1 & $(2.8,5.0,6.0)$ & $(6.6,8.2,9.0)$ & $(4.0,5.6,7.0)$ \\
\hline C2 & $(4.6,7.0,8.0)$ & $(5.8,7.6,8.8)$ & $(5.2,8.0,9.2)$ \\
\hline C3 & $(4.8,6.2,7.2)$ & $(3.4,6.0,7.4)$ & $(4.8,6.2,7.2)$ \\
\hline
\end{tabular}


Step 6: According to the Equation (7), calculate the $\operatorname{FBV}\left(\tilde{f}_{j}^{*}\right)$ value and the $\operatorname{FWV}\left(\tilde{f}_{j}^{-}\right)$value as below,

C1: $\tilde{f}_{j}^{*}(6.6,8.1,9.0) ; \tilde{f}_{j}^{-}(2.8,5.0,6.0)$

C2: $\tilde{f}_{j}^{*}(5.8,8.0,9.2) ; \tilde{f}_{j}^{-}(4.6,7.0,8.0)$

C3: $\tilde{f}_{j}^{*}(4.8,6.2,7.4) ; \tilde{f}_{j}^{-}(3.4,6.0,7.2)$

Step 7: After calculating the FBV and FWV, this study accord the Equation (8), (9) to find the value about the $\tilde{S}_{i}, \tilde{R}_{i}$ :

$\mathrm{A} 1: \tilde{S}_{i}(1.0000,1.3800,2.4600) ; \tilde{R}_{i}(0.5000,0.7000$, $0.8600)$

A2: $\tilde{S}_{i}(0.5000,0.9400,0.2867) ; \tilde{R}_{i}(0.5000,0.6600$, $0.2867)$

A3: $\tilde{S}_{i}(0.5921,0.5525,1.3267) ; \tilde{R}_{i}(0.3421,0.5525$, $0.7800)$

Step 8: Determine $\tilde{S}^{*}, \tilde{S}^{-}, \tilde{R}^{*}, \tilde{R}^{-}$value by applying Equation (10).

$\tilde{S}^{*}(0.5000,0.5525,0.2867)$;

$\tilde{S}^{-}(1.0000,1.3800,2.4600)$;

$\tilde{R}^{*}(0.3421,0.5525,0.2867)$;

$\tilde{R}^{-}(0.5000,0.7000,0.8600)$.

Step 9: According to the Equation (11), computing the $\tilde{Q}_{i}$ value and presented in terms of Equation (12) (16) as Table 6.

Table 6. Index $\tilde{Q}_{i}, Q_{i}$ and rank for each brand.

\begin{tabular}{|c|c|c|c|}
\hline$m$ & $\tilde{Q}_{i}$ & $Q_{i}$ & Rank \\
\hline A1 & $(1.0000,1.0000,1.0000)$ & 1.0000 & 3 \\
\hline A2 & $(0.5000,0.5985,0.0000)$ & 0.3662 & 2 \\
\hline A3 & $(0.0921,0.0000,0.6695)$ & 0.2539 & 1 \\
\hline
\end{tabular}

The $D Q$ value is 0.5 , and $Q\left(a^{\prime \prime}\right)-Q\left(a^{\prime}\right)=0.7461$, so $Q\left(a^{\prime \prime}\right)-Q\left(a^{\prime}\right) \geq \mathrm{D} Q$.

Step 10: Acceptable stability in decision making as $Q_{i}: \mathrm{A} 3>\mathrm{A} 2>\mathrm{A} 1, S_{i}: \mathrm{A} 3>\mathrm{A} 2>\mathrm{A} 1, R_{i}: \mathrm{A} 3>\mathrm{A} 2>\mathrm{A} 1$.The smallest value for $Q_{i}$ indicates the better alternative performance, so the brand A3 has the first priority.

\section{CONCLUSION}

The results show that Fuzzy VIKOR is helpful in assisting luxury brands in purchasing decisions.
General quantitative expressions cannot fully explain the complexity of the decision-making process criteria. The fuzzy VIKOR method is based on the largest group utility with the smallest regret of alternatives, so it can become an important reference module in the complex purchase decision of consumers. This research can also provide brand managers of luxury goods or other consumer products with another way of thinking, assisting them in making more correct marketing communication decisions with consumers, and using budgets in correct communication.

\section{AUTHORS' CONTRIBUTIONS}

Conceptualization, Tien-Chin Wang; Formal analysis, Yen-Ying Huang; Investigation, Yen-Ying Huang; Methodology, Tien-Chin Wang; Supervision, Tien-Chin Wang; Validation, Tien-Chin Wang; Visualization, Yen-Ying Huang; Writing-original draft, Yen-Ying Huang; Writing-review \& editing, Tien-Chin Wang.

\section{REFERENCES}

[1] Kapferer, J. N., \& Bastien, V, 2012. The luxury strategy: Break the rules of marketing to build luxury brands. Kogan page publishers.

[2] Shukla, P., Banerjee, M., \& Singh, J, Customer commitment to luxury brands: Antecedents and consequences. Journal of Business Research, 2016, 69(1), 323-331.

DOI:

https://doi.org/10.1016/j.jbusres.2015.08.004

[3] Kim, K. H., Ko, E., Xu, B., \& Han, Y, Increasing customer equity of luxury fashion brands through nurturing consumer attitude. Journal of Business Research, 2012, 65(10), 1495-1499. DOI: https://doi.org/10.1016/j.jbusres.2011.10.016

[4] Bain, \& Co, Luxury Goods Worldwide Market Study Fall-Winter 2015: A Time to Act-How Luxury Brands Can Rebuild to Win. Paris: Bain \& Co.

[5] Kapferer, J. N., \& Laurent, G, Where do consumers think luxury begins? A study of perceived minimum price for 21 luxury goods in 7 countries. Journal of Business Research, 2016, 69(1), pp. $332-340$.

DOI:

https://doi.org/10.1016/j.jbusres.2015.08.005

[6] Chevalier, M., \& Mazzalovo, G, 2008. Luxury brand management: a world of privilege. John Wiley \& Sons.

[7] Wiedmann, K. P., Hennigs, N., \& Siebels, A, Measuring consumers' luxury value perception: a cross-cultural framework. Academy of Marketing Science Review, 2007, 1. 
[8] Chen, L.Y., \& Wang, T. C, Optimizing partners' choice in IS/IT outsourcing projects: the strategic decision of fuzzy VIKOR. International Journal of Production Economics, 2009, 120(1), 233-242. DOI: https://10.1016/j.ijpe.2008.07.022

[9] Zadeh, L. A, Fuzzy sets. Information and Control, 1965, 8, 338-353. DOI: https://10.1016/S0019$9958(65) 90241-\mathrm{X}$

[10] Opricovic, S., \& Tzeng, G. H, Compromise solution by MCDM methods: A comparative analysis of VIKOR and TOPSIS. European Journal of Operational Research, 2004, 156, 445-455. DOI: https://10.1016/S0377-2217(03)00020-1

[11] Aaker DA, Joachimsthaler E. 2002. Brand leadership. Academy of Marketing Science. 30(2): 175-178.

[12] Insch, G. S., \& McBride, J. B, The impact of country-of-origin cues on consumer perceptions of product quality: A binational test of the decomposed country-of-origin construct. Journal of business research, 2004, 57(3), 256-265. DOI: https://doi.org/10.1016/S0148-2963(02)00323-5

[13] Zeithaml, V. A, Consumer perceptions of price, quality, and value: a means-end model and synthesis of evidence. Journal of marketing, 1988, 52(3), 2-22. DOI: https://doi.org/10.2307/1251446

[14] Petrick, J. F, Development of a multi-dimensional scale for measuring the perceived value of a service. Journal of leisure research, 2002, 34(2), 119-134.

DOI: https://doi.org/10.1080/00222216.2002.11949965

[15] Kotler P, Armstrong G. 2007. Principle of Marketing (12th ed.). New Jersey: Prentice Hall.

[16] Narayana, C. L, Aggregate images of American and Japanese products-Implications on international marketing. Columbia Journal of World Business, 1981, 16(2), 31-35.
[17] Roth, M. S., \& Romeo, J. B, Matching product catgeory and country image perceptions: A framework for managing country-of-origin effects. Journal of international business studies, 1992, 23(3), 477-497. DOI: https://doi.org/10.1057/palgrave.jibs.8490276

[18] Martin, I. M., \& Eroglu, S, Measuring a multidimensional construct: country image. Journal of business research, 1993, 28(3), 191-210. DOI: https://doi.org/10.1016/0148-2963(93)90047-S

[19] Rao, A. R., \& Monroe, K. B, The effect of price, brand name, and store name on buyers' perceptions of product quality: An integrative review. Journal of marketing Research, 1989, 26(3), 351-357. DOI: https://doi.org/10.1177/002224378902600309

[20] Biehal, G., \& Chakravarti, D, Information accessibility as a moderator of consumer choice. Journal of Consumer Research, 1983, 10(1), 1-14. DOI: https://doi.org/10.1086/208941

[21] Peter, J. P., Olson, J. C., \& Grunert, K. G. 1999. Consumer behavior and marketing strategy.

[22] Brucks, M, The effects of product class knowledge on information search behavior. Journal of consumer research, 1985, 12(1), 1-16. DOI: https://doi.org/10.1086/209031

[23] Wang, T. C., \& Chang, T. H. 2005, April. Fuzzy VIKOR as a resolution for multicriteria group decision-making. In The 11th International Conference on Industrial Engineering and Engineering Management pp. 352-356. Paris, France: Atlantis Press.

[24] Brucks, M, The effects of product class knowledge on information search behavior. Journal of consumer research, 1985, 12(1), 1-16. DOI: https://doi.org/10.1086/209031 